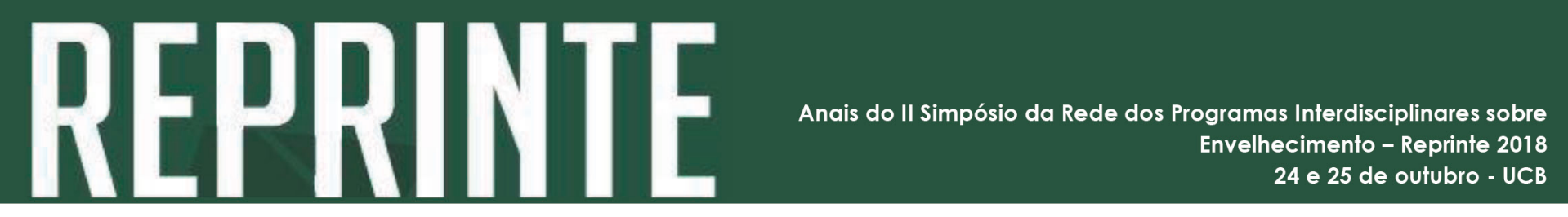

http://dx.doi.org/10.5335/rbceh.v16i1.9784

\title{
15) Risco de longevidade e mecanismos de proteção nos Fundos de Pensão: revisão sistemática de literatura
}

\author{
Vagner Lacerda Ribeiro'; Isabelle Patricia Freitas Soares Chariglione², \\ Henrique Salmazo da Silva
}

\section{Resumo}

O risco de longevidade é conceituado como a probabilidade de que os recursos destinados para o pagamento das aposentadorias acabem antes do final da vida do indivíduo. Este trabalho tem por objetivo apresentar dados preliminares da revisão sistemática de literatura sobre os principais mecanismos para proteção (hedge) desse risco de longevidade em fundos de pensão. Foram identificados 40 trabalhos aplicados diretamente aos fundos de pensão. As principais estratégias de hedge encontradas foram Anuidades, Seguros, Mercado de Capitais e Títulos Públicos, representando $72 \%$ do total. Derivativos, Títulos Privados e outros representaram $28 \%$. Um dos trabalhos citou a proposição de uma estratégia baseada em fundos que investem em empresas de pesquisa do bem-estar, saúde e longevidade. Propõe-se uma reflexão sobre o benefício duplo desses investimentos como instrumentos de hedge e contribuição para a saúde, bem-estar e longevidade da população global.

Palavras-chave: Palavras Chave: Risco de Longevidade, Fundos de Pensão e Estratégias de Proteção

\section{0 envelhecimento populacional e os fundos de pensão}

O envelhecimento populacional é o desafio social do século XXI, demandando políticas sociais e econômicas sustentáveis e viáveis.

O Sistema de Previdência possui a função de prover o pagamento de aposentadorias e pensões até o fim da vida, mas questiona-se se de fato será capaz de arcar com os custos relacionados a longevidade, entre eles o aumento de idosos dependentes, a diminuição de contribuições e os elevados custos de saúde. Isso porque, estima-se que em 2050 1/4 da população mundial seja composta por idosos, o que totalizará 2 bilhões de habitantes. Ademais, 2/3 da

1 Doutorando em Gerontologia no Programa de Pós-Graduação em Gerontologia, Universidade Católica de Brasília. Endereço para correspondência: QS 7, Lote 1, Águas Claras, Brasília - CEP: 71966-700, Brasília, (DF) Brasil. E-mail: vagnerlr@uol.com.br

2 Professores no Programa de Pós-Graduação em Gerontologia, Universidade Católica de Brasília. E-mails (na ordem em que aparecem): isabelle.chariglione@ucb.br; henriquesalmazo@gmail.com 
população idosa possui alguma condição crônica de saúde que exige cuidados complexos e mais recursos de saúde (YASOBANT, 2018).

Segundo dados da Organização para Cooperação e Desenvolvimento Econômico (OECD, 2017) dentro dos sistemas previdenciários, os Fundos de Pensão concentram boa parte dos ativos (investimentos) mundiais, somando cerca de US\$26 trilhões. O aumento da longevidade também preocupa o setor sendo que a literatura tem explorado o assunto a partir da análise e planejamento de estratégias sistêmicas em que a longevidade é tratada como um risco, onde o risco de longevidade é a probabilidade de que os recursos para o pagamento das aposentadorias cessem antes do fim da vida dos participantes.

A busca por investimentos adequados pode minimizar o impacto desses desequilíbrios, sendo que os investimentos em saúde, bem-estar e estilo de vida desta população podem também ser destacados como fatores de proteção (hedge). Nessa lógica os Fundos de Pensão poderiam direcionar parte dos seus investimentos para melhorar a sustentabilidade do sistema ao investir seus recursos em produtos e serviços que convirjam para a qualidade de vida na idade madura, amortizando o impacto do aumento de idosos no sistema.

Este trabalho tem por objetivo apresentar dados preliminares sobre o panorama das pesquisas realizadas na última década sobre o risco de longevidade em fundos de pensão e os principais mecanismos que estão sendo utilizados como hedge.

\section{Material e Método}

Foi conduzida uma revisão de literatura mundial, utilizando como palavras chave risco de longevidade, "Longevity Risk", e fundos de pensão, "Pension Funds". Foram incluídos estudos publicados entre 2007 a 2017, revistos por pares, no idioma de língua inglesa. O site para busca foi o Portal CAPES, tendo como principais fontes o ProQuest LLC, Cengage Learning, Inc., Emerald Insight Journals, ScienceDirect (Elsevier B.V.) e Springer Science \& Business Media B.V. Foi efetuada análise descritiva dos artigos, tabulando, contando e classificando em planilha Excel todos os artigos. Adotou-se como critério a exclusão de trabalhos que não tinham relação direta com as questões do Risco de Longevidade nos Fundos de Pensão. Dos 205 estudos encontrados, foram selecionados 148.

\section{Resultados}

A análise preliminar da literatura indicou quatro principais grupos sendo que $38 \%$ das publicações tratavam sobre Modelagem e Precificação do Risco de Longevidade; $38 \%$ sobre Estratégias de Proteção (hedge); 11\% Sistema de Previdência, Seguridade e Estado, e 13\% Planos e Fundos de Pensão. Dos 148 trabalhos, 56 tratavam da proteção do risco de longevidade para previdência, sendo que destes apenas 40 estão diretamente associados aos fundos de pensão.

Com relação as estratégias de hedge, $25 \%$ dos estudos tratavam sobre Anuidades e Seguros; $17 \%$ sobre Ações e Equity, 17\% sobre Títulos Públicos; 14\% sobre Imóveis, 10\% sobre 
Derivativos (swaps e opções), 11\% sobre Títulos Privados e 6\% versavam sobre outras soluções, conforme gráfico abaixo:

Figura 1. Estratégia de hedge utilizada pelos estudos sobre fundos de pensão, revisão da literatura internacional, 2007-2017

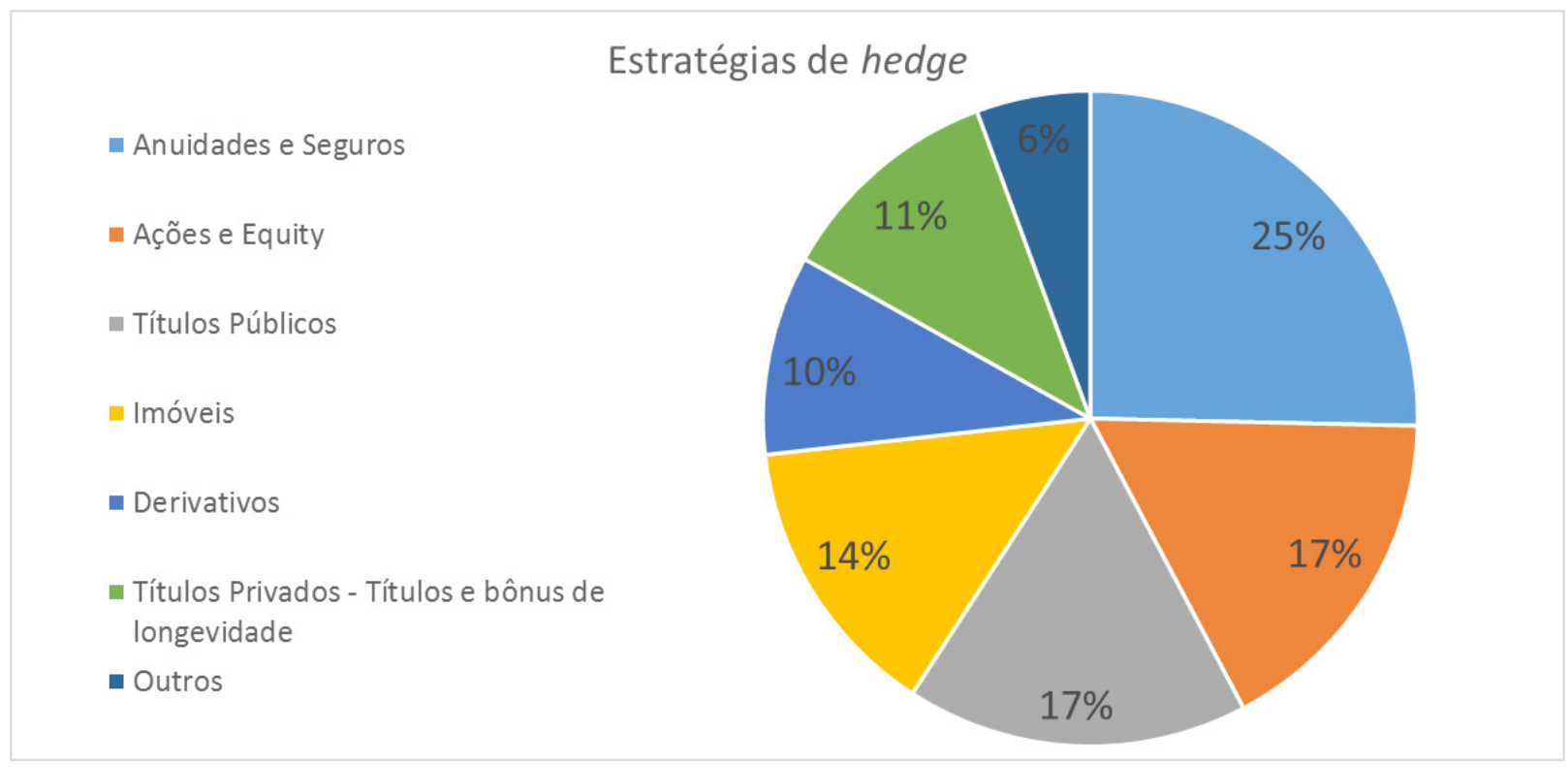

Começando pelas Anuidades e Seguro, o estudo (FONG et al, 2011) trata do longo período de acumulação dos Planos de Contribuição Definida e levanta dúvidas sobre a sustentabilidade do pagamento de benefícios. Os autores descrevem que o Fundo Central de Previdência (CPF) de Cingapura resolveu liquidar os Planos de Contribuição Definida e arcar com o pagamento de anuidades para todos os participantes, como um segurador. Em complemento, o estudo de Lin e Tsai (LIN et al, 2013), propõe estratégias combinadas de produtos em uma carteira de seguros, apresentando os resultados em que o matching pode cobrir significativamente os riscos de mortalidade / longevidade.

$\mathrm{Na}$ sequência, para exemplificar o efeito dos investimentos efetuados no mercado de capitais, foi selecionado o artigo de Gerber e Weber (GERBER et al, 2007) o qual aborda a questão a partir dos estudos da experiência dos fundos de pensão na Suíça. De acordo com o estudo, existe uma maior propensão para alocação de investimentos em ações e menor em imóveis no período em que a faixa etária dos participantes ainda é menor. Por outro lado, também demonstrou uma aversão dos Fundos de Pensão em investimentos em ações na fase de pagamento de benefícios.

Outro estudo, como o de Yang et al. (2016), analisou a criação de megafundos de saúde, com enfoque na performance de um megafundo de câncer, o qual recebe investimentos mediante instrumentos de capital (equity) e dívida (empréstimos) e orienta-se para o desenvolvimento de pesquisas e medicamentos ao tratamento do câncer. Os resultados remetem para uma estrutura de securitização que pode atender os fundos de pensão. Os autores concluem que esses investimentos podem proporcionar proteção para o risco de longevidade e promoção da saúde, bem-estar e longevidade. 
Já os estudos sobre investimentos em Títulos Públicos destacam-se estudo aplicado ao mercado Australiano com a proposta de investimentos em ativos livre de risco, como forma de estabelecer uma estrutura de pagamentos de aposentadorias mais estável (GAY, 2008).

Com relação ao hedge que focalizou investimentos em Imóveis Doling e Ronald (2012) destacaram a Hipoteca Reversa, descrevendo o comportamento dos mercados do leste asiático, no caso Japão, Cingapura, Coreia do sul e Taiwan. Trata-se de um conjunto de mecanismos ofertados pelo mercado privado e setor público em que os imóveis dos idosos podem ser convertidos em pagamentos de rendas para os aposentados.

Sobre as alternativas de hedge que utilizaram derivativos, concentraram suas operações em swaps, com aplicação de swaps de anuidade e das opções de cupom de reinvestimento variável da vida útil, Bowden (BOWDEN, 2009). Já as estratégias focalizadas em títulos privados (DENUIT et al, 2007), sugerem que a oferta de bônus de longevidade pode ser precificada a partir de índices de mortalidade divulgados de forma pública e ofertados diretamente pelas seguradoras.

Na sequência, o aumento do prazo de aposentadoria e de contribuição, são explorados. O aumento do prazo também vem sendo utilizado pela previdência social como forma de se tentar equilibrar o déficit fiscal em todo o mundo. A esse respeito, o trabalho de Di Giacinto (2012) aborda a questão a partir da análise do "tempo ótimo para a anuitização" em que o aposentado deve escolher o momento certo de sua aposentadoria. Quanto ao aumento da contribuição o assunto é explorado no trabalho de Calciano e Tirelli (CALCIANO et al, 2008) realizado na Holanda e com base em duas análises situadas no aumento da contribuição ou na redução da indexação do pagamento das contribuições à índices de inflação e aumento de produtividade.

Por fim, merecem destaque também dois trabalhos que tratam da estratégia de transferência do risco para o participante. Esse assunto é abordado no artigo de Boyer et al. (2014) em que é estudada a forma como as empresas no mercado americano vêm se "livrando" dos planos de benefício definido e transferindo o risco da aposentadoria para os participantes. Outra análise foi desenvolvida por Milevsky e Song (2010) o qual traz uma reflexão sobre a forma como algumas empresas parecem tratar a eliminação do risco de longevidade fazendo com que seus trabalhadores trabalhem até a exaustão nos últimos anos laborais, de forma a terem baixa expectativa de vida após a aposentadoria.

\section{Conclusões}

Aproximadamente 1/3 dos trabalhos acadêmicos recentes que abordam Risco de Longevidade e Fundos de Pensão discutem diretamente o assunto proteção (hedge) para risco de longevidade e as estratégias lançadas ao setor são majoritariamente anuidades (seguridade), ações e participações (equity), investimentos em títulos públicos (bond's), imóveis, derivativos e títulos privados. Chamou a atenção o fato de apenas um dos trabalhos ter abordado diretamente os investimentos em questões de saúde e bem-estar.

Se boa parte do aumento da longevidade está associada ao aumento da qualidade de vida e bem-estar das pessoas, seria natural pensar que haveria a busca de proteção desse risco em 
negócios relacionados à longevidade, no mercado de capitais. Essa quebra de expectativa pode estar associada a aparente falta de interlocução entre a Gerontologia, os setores de Saúde e a Economia; a ausência de uma pauta social para as questões do envelhecimento e/ou ao desconhecimento dos gestores dos fundos sobre estratégias de investimentos focadas no processo de envelhecimento e bem-estar na velhice.

Concluindo, sugere-se que os investimentos em "negócios da longevidade" poderiam ser mecanismos de hedge viáveis e ao mesmo tempo oportunidades frente a escassez de produtos, serviços e empregos voltados ao envelhecimento. Contudo, a viabilidade e as aplicações dos investimentos devem ser melhor estudadas, com vistas na formulação de soluções sistêmicas e integradas para lidar com a complexidade associada ao envelhecimento da população mundial.

\section{Risk of longevity and protection mechanisms in the Pension Funds: a systematic literature review}

\section{Abstract}

The risk of longevity is conceptualized as the probability that the resources destined for the payment of the retirements end before the end of the life of the individual. This paper aims to present preliminary data on the systematic review of the literature on the main mechanisms for hedging this longevity risk in pension funds. A total of 40 jobs were identified directly applied to pension funds. The main hedge strategies found were Annuities, Insurance, Capital Markets and Public Securities, representing $72 \%$ of the total. Derivatives, Private Securities and other accounted for $28 \%$. One of the papers cited the proposition of a fund-based strategy that invests in wellness, health and longevity research firms. It is proposed to reflect on the double benefit of these investments as instruments of hedge and contribution to the health, well-being and longevity of the global population.

Keywords: Risk of Longevity, Pension Funds and Protection Strategies

\section{Referências}

BOWDEN, RJJJoPE. Finance. Lifecycle derivatives and retirement income assurance using long-term debt. 2009;8(3):361-90.

BOYER, M.M.; MEJZA, J.; STENTOFT, L.J.R.M. Review I. Measuring longevity risk: An application to the Royal Canadian mounted police pension plan. 2014;17(1):37-59.

CALCIANO, F.L.; TIRELLI, M.J.E.V. Public versus private old-age pensions in Europe. 2008;7(2):277-86.

DENUIT, M.; DEVOLDER, P.; GODERNIAUX, ACJJoR. Insurance. Securitization of Longevity Risk: Pricing Survivor Bonds With Wang Transform in the Lee-Carter Framework. 2007;74(1):87-113.

DI GIACINTO, M.; VIGNA, EJCEJoOR. On the sub-optimality cost of immediate annuitization in DC pension funds. 2012;20(3):497-527.

DOLING, J.; RONALD, R.J.A. Society. Meeting the income needs of older people in East Asia: Using housing equity. 2012;32(3):471-90.

FONG, J.H.; MITCHELL, O.S.; KOH, BSJJoR. Insurance. Longevity risk management in Singapore's national pension system. 2011;78(4):961-82. 
GAY, RJTJoR. Mean-variance optimality of a retirement lump sum conversion strategy: implementation in Australia. 2008;10(4):113.

GERBER, D.S.; WEBER, RJJoPE, Finance. Demography and investment behavior of pension funds: evidence for Switzerland. 2007;6(3):313-37.

LIN, T; TSAI, CC-LJIM. Economics. On the mortality/longevity risk hedging with mortality immunization. 2013;53(3):580-96.

MILEVSKY, M. A.; SONG, KJJor. insurance. Do markets like frozen defined benefit pensions? An event study. 2010;77(4):893-909.

OECD. Pensions at a Glance 2017/2017.

YANG, X.; DEBONNEUIL, E.; ZHAVORONKOV, A.; MISHRA, B.J.O. Cancer megafunds with in silico and in vitro validation: accelerating cancer drug discovery via financial engineering without financial crisis. 2016;7(36):57671.

YASOBANT, S. Comprehensive public health action for our aging world: the quintessence of public health policy. SAGE Publications Sage UK: London, England; 2018. 